\title{
DISCRIMINAÇÃO NO TRATAMENTO JURÍDICO RECEBIDO PELAS MULHERES NOS CÓDIGOS PENAIS DO SÉCULO XIX
}

Leonardo Machado Acosta
Carlos Henrique Gasparoto

\section{RESUMO}

Neste artigo é realizada uma análise da legislação penal do século XIX e também de caso prático em relação ao tratamento recebido pela mulher nos crimes contra a honra. Naqueles delitos, para a mulher se enquadrar como vítima, deveria possuir certas qualidades previamente estabelecidas pela sociedade; desta forma, o ordenamento jurídico muitas vezes discriminava algumas mulheres e restringia seus direitos simplesmente por elas não se enquadrarem no modelo ideal feminino firmado pela sociedade patriarcal vigente na época.

Palavras-chave: Discriminação. Mulher honesta. Século XIX. Desigualdade de Gênero.

\section{INTRODUÇÃO}


Neste artigo será analisada a condição jurídica das mulheres quando se tratava de crimes contra a honra no século XIX. Naquele período a sociedade brasileira era marcada pela centralidade da figura masculina, reduzindo o papel da mulher ao âmbito doméstico, exigindo um modelo feminino que se encaixasse nesse papel social; dessa forma, mulheres que não seguissem este padrão acabavam por ter seus direitos reduzidos ou negados.

Esta análise em perspectiva histórica é válida tendo em vista possibilitar uma melhor compreensão de alguns dos motivos fundamentais das lutas feministas; proporciona também notar como esta forma de tratamento dado às mulheres no século XIX, por muitas vezes, ainda é adotada nos dias de hoje, submetendo as mulheres ao papel de guardiã da honra e dos bons costumes, exigindo delas uma forma de se comportar previamente determinada pela sociedade, para que somente assim possam exercer os seus direitos plenamente.

No âmbito deste artigo, serão analisadas partes da legislação penal do século XIX, mais especificadamente os artigos que tratam dos crimes contra a honra, assim como também será apreciado um processo penal referente a um crime de rapto ocorrido na comarca de Franca no ano de 1898. Dentro deste estudo ficará nítida a maneira como a mulher, vítima de crimes contra a honra, era tratada tanto pelo direito dentro da lei, como também em um caso prático.

\section{DISCRIMINAÇÃO PRESENTE DENTRO DA LEGISLAÇÃO E DA SOCIEDADE}

Os Códigos Penais do século XIX, no que se referia aos delitos "contra a segurança da honra", impunham certas características que a mulher deveria possuir para o crime ser consumado, ou seja, a mulher deveria obedecer às condições previstas em lei para ser enquadrada como vítima deste tipo de delito. Nesta seção, tanto o Código Penal do ano de 1830 (capítulo II dos crimes contra a segurança da honra), assim como o de 1890 (título VIII dos crimes contra a segurança da honra e honestidade das famílias e do ultraje público ao pudor) descreviam os crimes que denegriam a honra das mulheres, e como consequência, a honra das famílias. Dentre esses delitos figurava o crime de Rapto (que no decorrer do 
texto será analisado através de um processo penal do ano de 1898). Segundo o artigo 270 do Código Penal de 1890, rapto se configurava por:

Tirar do lar domestico, para fim libidinoso, qualquer mulher honesta, de maior ou menor idade, solteira, casada ou viuva, attrahindo-a por seducção ou emboscada, ou obrigando-a por violencia, não se verificando a satisfação dos gosos genesicos. ${ }^{40}$

Vale observar que a expressão "mulher honesta", utilizada para qualificar o sujeito passivo do crime em questão, possuía uma conotação diferente da que atualmente é atribuída a esse termo. Para esta característica ser concedida a mulher e, consequentemente, tornar-se possível de ela ser enquadrada como vítima nesses crimes, ela deveria conservar a sua honra, vivendo sob a autoridade de seu pai, marido ou irmão, circunscrita ao círculo familiar, nos modelos típicos da sociedade patriarcal do século XIX. Caso ela não possuísse tal característica, os crimes não se consumariam, ela não teria o mesmo direito que as demais mulheres que estavam enquadradas no padrão social vigente. Neste sentido, Taís Elaine do Nascimento Vieira caracteriza a forma como a sociedade e os ordenamentos jurídicos tratavam as mulheres no século XIX:

As mulheres antes do casamento eram resguardadas do ambiente público pelos seus pais para manterem intacta sua honra. Ao se casarem perdiam a identidade jurídica que nunca possuíram, porque quando crianças e adolescentes eram consideradas menores e incapazes para os atos da vida jurídica, e deviam ser representadas ou assistidas pela figura do pai, pois eram vistas como unidade sob o comando do homem-pai. Com o casamento a situação jurídica da mulher continuava nula; qualquer ato da vida

40 Decreto $N^{\circ}$ 847, de 11 de outubro de 1890. Codigo Penal dos Estados Unidos do Brazil. Disponível em: <http://www2.camara.leg.br/legin/fed/decret/1824-1899/decreto847-11-outubro-1890-503086-publicacaooriginal-1-pe.html>. Acesso em: 23 jul. 2015. 
civil deveria ser praticado com a assistência do marido. ${ }^{41}$

Fica nítido que os gêneros masculino e feminino recebiam tratamentos diferenciados: nenhum artigo do Código Penal de 1890 impunha a característica de homem "honesto" como condição para que ele pudesse ser enquadrado como vítima de um crime. Era valorizada pelo Código somente a honestidade da mulher, pois era ela quem representava a honra da família, merecendo desta forma um tratamento privilegiado por parte do Direito. Conforme acentua Carlos Martins Junior:

Seguindo esse raciocínio, as noções de "honra" e "honestidade" das famílias presentes no Titulo $8^{\circ}$ do Código Penal de 1890 confundiam-se com as noções de "honra" e "honestidade" feminina, a indicar que o alvo específico da legislação eram as mulheres, a quem caberia incorporar tais noções para que fossem as mesmas estendidas à família. ${ }^{42}$

Era fato comum culpar a própria vítima como principal responsável por esse tipo de crime. Viveiros de Castro afirmava que: "É de justiça responsabilizar em primeiro lugar a própria mulher. Dominada pela ideia errônea, subversiva, de sua emancipação, ella faz tudo que de si depende para perder o respeito, a estima e a consideração dos homens". ${ }^{43}$ Ou seja, a mulher que não se submetesse à autoridade patriarcal, que pensasse ser "livre" para viver a sua vida, caso fosse vítima de um delito contra a sua "honra" possuía o risco de não ter o direito de exigir a punição do criminoso, pois poderia ser acusada de ser culpada pelo crime

41 VIEIRA, Taís Elaine do Nascimento. Status jurídico da mulher brasileira no século XIX. Revista Transdisciplinar Logos e Veritas, Vol. 01, $\mathrm{n}^{\circ}$ 01, 2014, pp. 42-46, ISSN 23189614. Disponível em: http://revistalogoseveritas.inf.br/lev/wpcontent/uploads/2014/01/09_Status-juridico-damulher-brasileira-no-seculo-XIX.pdf Acesso em: 23 jul. 2015. p. 3.

42 MARTINS, Carlos. Saber Jurídico, Criminalidade e Controle da Sexualidade na "República dos Bacharéis". V Congresso Internacional de História, 2011, ISSN 21756627 (CD-ROM), ISSN 2175-4446 (ON-LINE). Disponível em: http://www.cih.uem.br/anais/2011/trabalhos/42.pdf . Acesso em: 23 jul. 2015. p. 6.

${ }_{43}$ CASTRO, Francisco José Viveiros de. Os Delictos contra a honra da mulher. 2. ed. Rio de Janeiro: Livraria Editora Freitas Bastos, Freitas Bastos \& CIA, 1932. p. 21. 
cometido. Para Viveiros de Castro, a mulher que não seguisse os bons costumes e que não fosse recatada deveria ter seus direitos de certa forma "restringidos", pois segundo a lógica da época, ela mesma poderia ter sido a verdadeira culpada pelos delitos contra a sua pessoa.

Neste sentido, Viveiros de Castro acentua o modelo ideal da educação para a mulher da época:

A antiga educação da mulher recatada e tímida, delicada sensitiva evitando os contatos ásperos e rudes da vida, foi desprezada como cousa anachronica e ridícula: e temos hoje a mulher moderna, vivendo nas ruas, sabendo tudo, discutindo audaciosamente as mais escabrosas questões, sem refreio religioso, avisa unicamente de luxo e sensações, vaidosas e fúteis, preza fácil e muita vez até espontaneamente oferecida á conquista do homem. ${ }^{44}$

Castro criticava severamente a educação dada às mulheres que não as transformasse em mães de famílias, presas à "intimidade silenciosa do lar", pois essa educação, a qual ele chamava de "moderna", iria transformar as mulheres em "bonecas de salão, vaidosas e fúteis, ávidas de bailes, theatros e concertos, tendo como única ambição supplantar as rivais pelo luxo de suas toilettes ou pela riqueza de suas joias." ${ }^{45}$. Ou seja, a menina que não recebesse a educação ideal correria o risco de ser mal vista pela sociedade, e até mesmo ter sua "honestidade" questionada.

Vale notar que qualquer menina que estivesse fora do convívio familiar, ou até mesmo mulheres que tinham de sair para trabalhar fora de casa, poderiam ser consideradas "desonestas". Por estarem vivendo fora do seio familiar, não teriam a vigilância constante dos homens da família para assegurar que a sua honradez e decência fosse resguardada. Pelo contrário, as mulheres que trabalhavam fora de casa, ou não viviam com a presença da família, estariam expostas ao "perigo" apresentado pelo mundo, no qual elas poderiam perder a sua ingenuidade, e como consequência disso, não seriam boas "guardiãs" da honra familiar perante a

${ }^{44}$ CASTRO, Francisco José Viveiros de. Os Delictos contra a honra da mulher. 2. ed. Rio de Janeiro: Livraria Editora Freitas Bastos, Freitas Bastos \& CIA, 1932. p. 21-22.

45 Idem. p. 22. 
sociedade patriarcal. Desta forma, dificilmente conseguiriam ser enquadradas como vítimas nesse tipo de crime, que eram tipificados justamente para manter a honra das famílias protegidas. Deste modo, explica Carlos Martins Junior:

Não era por acaso, portanto, que em processos crime envolvendo mulheres e meninas trabalhadoras, 0 estigma de "desonestas" por andarem sós às ruas, ainda que precisassem fazê- lo por ordem dos próprios patrões ou pela necessidade de ir e vir do trabalho, lhes fosse aplicado pelos advogados dos réus. Na realidade, o que se esperava delas, era que reconhecessem o "seu lugar" na sociedade, sob o risco de, paradoxalmente, se transformarem em responsáveis pelos abusos sexuais que viessem a sofrer. ${ }^{46}$

É considerável destacar que aqui existia também um preconceito de classe, pois somente as famílias menos abastadas tinham a necessidade de que as filhas e esposas se afastassem do ambiente doméstico para trabalhar. Desta forma, muitas vezes a "honestidade" da mulher poderia ser associada também a sua classe econômica: as mulheres ricas não necessitavam sair de casa e recebiam a educação "apropriada" para a sociedade. Já as mulheres de origem mais pobre tinham de trabalhar fora de casa para ajudar com o sustento familiar e, por muitas vezes, não recebiam a educação "adequada", sendo assim sua "honestidade" não era tão confiável quanto a das mulheres mais abonadas economicamente. Viveiros de Castro expõe claramente a visão da sociedade sobre estas mulheres:

Nas classes proletarias a fabrica matou a familia, dissolvendo os laços que a prendem e unem. $\mathrm{O}$ marido trabalha em uma fabrica, a mulher em outra, separada delle, exposta a todas as seduções. Meninas de quinze annos vão sosinhas aos ateliers de

\footnotetext{
46 MARTINS, Carlos. Saber Jurídico, Criminalidade e Controle da Sexualidade na "República dos Bacharéis". V Congresso Internacional de História, 2011, ISSN 21756627 (CD-ROM), ISSN 2175-4446 (ON-LINE). Disponível em: http://www.cih.uem.br/anais/2011/trabalhos/42.pdf . Acesso em: 23 jul. 2015. p. 8.
} 
costuras, voltam á noite sós para a casa, tentadas, perseguidas. ${ }^{47}$

Para a mulher se encaixar neste padrão tão exigente de "honestidade" ela deveria seguir um modelo que, por muitas vezes, era impossível. Somente um seleto grupo do gênero feminino se enquadrava neste padrão e tinha todos os seus direitos garantidos, grupo este pertencente em quase sua totalidade à classe abastada, que tinha a oportunidade de receber a educação adequada e também possuía o luxo de viver somente dentro da casa da família. Fazendo esta exigência e distinção, o ordenamento jurídico comumente excluía as classes pobres, restringindo os seus direitos, pois essa classe não pertencia ao padrão necessário para ter todos seus direitos assegurados.

A legislação penal do século XIX, por várias vezes, fazia esta distinção entre mulher "honesta" e "desonesta": além do crime de rapto supracitado, outros crimes podem ser dados a título de exemplo, como o que dispunha sobre estupro, no artigo 222 do Código Criminal do Império do Brasil (1830): "Ter copula carnal por meio de violencia, ou ameaças, com qualquer mulher honesta.”. (art. 222, CP/1830). ${ }^{48}$

No contexto deste mesmo artigo referente ao crime estupro, é possível encontrar outra discrepância. Se a vítima de estupro fosse prostituta, a pena para o criminoso poderia ser reduzida drasticamente, como pode ser observado: "Penas - de prisão por tres a doze annos, e de dotar a ofendida. Se a violentada fôr prostituta. Penas - de prisão por um mez a dous annos.". ${ }^{49}$ (art. 222, CP/1830). Isto ocorre, pois o principal bem tutelado nesta norma não é a integridade física ou psicológica da vítima, mas sim os bons costumes, a honra da família. Desta forma, a "prostituta" ou a mulher que não fosse "honesta" não merecia a mesma proteção por parte do Direito que as demais, pois, aos olhos da sociedade daquela época, elas não possuíam o bem jurídico que a lei visava proteger.

Viveiros de Castro pensava ser um absurdo, um contrassenso jurídico classificar a violação de uma prostituta entre os crimes contra a

\footnotetext{
47 CASTRO, Francisco José Viveiros de. Os Delictos contra a honra da mulher. 2. ed. Rio de Janeiro: Livraria Editora Freitas Bastos, Freitas Bastos \& CIA, 1932. p. 22.

48 Lei de 16 de dezembro de 1830. Codigo Criminal do Imperio do Brazil. Disponível em: http://www.planalto.gov.br/ccivil_03/leis/LIM/LIM-16-12-1830.htm . Acesso em: 23 jul. 2015.

49 Ibidem.
} 
segurança da honra e da honestidade das famílias. Para ele, a mulher que faz comércio de seu corpo não possuía sentimento de honra ou dignidade, e quem abusasse dela não prejudicaria seu futuro, nem mancharia a sua reputação. A prostituta não possuía a honra, a honestidade como representante da família, ou seja, ela não possuía o bem jurídico tutelado pelo direito, e por isso ordenamento jurídico a diferenciava das demais mulheres consideradas "honestas", dando uma pena menor para quem violasse seu corpo, pois este corpo não guardava mais a honra e a decência que mereciam proteção. Desta forma, Viveiros de Castro diferenciava os efeitos do estupro na mulher "honesta" e nas prostitutas: para ele, os resultados não eram idênticos, pois "a prostituta não recebe a afronta que mancha indelevelmente a vida da mulher honesta.". ${ }^{50}$

Outro exemplo considerável é o referente ao crime de rapto, em que novamente era posto esta qualidade específica que o sujeito passivo do crime deveria apresentar. O jurista Macedo Soares acentua como um dos elementos essenciais do crime de rapto "que a raptada seja honesta, e como tal se presume a que vive em recato no seio da família.". ${ }^{51}$ Deixando evidente que novamente a mulher era vista como guardiã da honra da família, e que esta para conservar a sua "honestidade" deveria viver de forma "recatada" presa ao "ambiente familiar".

\section{FORMA DE TRATAMENTO RECEBIDA PELAS VÍTIMAS E COMO SE RESOLVIAM OS DELITOS CONTRA A HONRA NA PRÁTICA}

Para uma análise prática vamos tomar como exemplo alguns trechos de um processo referente ao crime de rapto, datado do ano de 1898, ocorrido na comarca de Franca. Nesse processo, uma moça foi raptada e seu pai fez a denúncia do crime. O trecho a seguir é referente à declaração de uma testemunha do caso; nota-se que esta testemunha tenta qualificar a vítima como mulher honesta, para que o "criminoso" possa ser sujeito às penas previstas para o crime: "Sabe que Noemia é solteira e

\footnotetext{
50 CASTRO, Francisco José Viveiros de. Os Delictos contra a honra da mulher. 2. ed. Rio de Janeiro: Livraria Editora Freitas Bastos, Freitas Bastos \& CIA, 1932. p. 124.

51 SOARES, Oscar de Macedo. Código Penal da República dos Estados Unidos do Brasil. 5. ed. Rio de Janeiro: H.Garnier, 1910. p. 544.
} 
honesta e que vivia em companhia de seus pais n'esta Cidade." ${ }^{52}$. Outra testemunha qualifica novamente a vítima da mesma forma, para deixar claro que ela poderia ser enquadrada como sujeito passivo deste delito em questão: "Disse mais que conhecia Noemia e sabe que ella é solteira e virgem e que vivia na casa paterna." ${ }^{53}$. Fica nítida a preocupação das testemunhas em intitular a vítima do crime como "honesta", tendo como argumentos para isto, a questão da virgindade da moça, ou deixando claro que ela vivia com seus pais dentro do seio familiar. Por esta menina ser detentora do título de "honesta", o crime praticado contra ela estaria colocando em risco a integridade moral de toda a sua família; desta forma, ela seria "digna" de ter o direito de ser qualificada como vítima deste crime, e o ordenamento jurídico teria o dever de protegê-la, punindo o culpado e tentando restituir a honra perdida.

Essa caracterização por parte das testemunhas sobre a vítima do crime era indispensável, pois através destes testemunhos buscava-se provar que a mulher realmente era honesta, ou seja, tímida, reclusa à convivência da família, e não uma mulher desvinculada do lar doméstico, independente, e que possivelmente estaria mentindo sobre o ocorrido, pois segundo Viveiro de Castro, eram esses dois tipos que mulheres que se apresentavam como vítimas dos delitos em questão.

Duas especies de mulheres apresentam-se perante a justiça como victimas de atentados contra a sua honra. Umas são em verdade dignas da protecção das leis e da severidade inflexível do juiz. Timidas, ingenuas, incautas, foram realmente victimas da força brutal do estuprador ou dos artifícios fraudulentos do seductor. Mas ha outras corrompidas e ambiciosas que procuram fazer chantage, especular com a fortuna ou a posição do homem, attribuindolhe a responsabilidade de uma seducção que não

\footnotetext{
52 Declaração dada por uma testemunha a fls. 7 do Processo $\mathrm{n}^{\circ} 1595$, cx. 76, 1898, processo este que se encontra no acervo do Arquivo Histórico Municipal "Capitão Hipólito Antônio Pinheiro" na cidade de Franca, São Paulo.

53 Declaração dada por uma testemunha a fls. 7 do Processo $\mathrm{n}^{\circ} 1595$, cx. 76,1898 , processo este que se encontra no acervo do Arquivo Histórico Municipal "Capitão Hipólito Antônio Pinheiro" na cidade de Franca, São Paulo.
} 
existiu, porque ellas propositalmente a provocaram, ou uma supposta violencia imaginaria, ficticia. ${ }^{54}$

Seguindo-se o mesmo processo, o autor do crime acabou por ser preso. Para que ele não sofresse as penas previstas pelo crime, ele casouse com a vítima, pois segundo o parágrafo único do artigo 276 do mesmo Código "Não haverá logar imposição de pena si seguir-se o casamento a aprazimento do representante legal da offendida, ou do juiz dos orphãos, nos casos em que lhe compete dar ou supprir o consentimento, ou a aprazimento da offendida, si for maior.".

Vemos, no trecho a seguir, o "criminoso" pedindo a extinção das penas em razão do casamento realizado:

Diz Lycurgo Alves Guimarães, que achando-se pronunciado por este juízo, como incurso no art 272 $\S 1^{\circ}$ do Código Penal por ser acusado de ter raptado a menor Noemia Sara Machado e tendo realizado o seu casamento com a mesma menor, vem por isso requerer a Vossa Excelência se designe em vista, da condição, julgar por sentença a perempção da acção intentada pela justiça pública contra o Suplicante, afim, de por termo, ao respectivo processo, visto não ter mais lugar a imposição, de pena conforme a disposição do art $276 \S$ único do citado código. ${ }^{55}$

Este "perdão" da pena em consequência do casamento ocorria em razão do matrimônio restituir a honra da família e da ofendida, ou seja, o bem jurídico que o Direito visava proteger não era mais ameaçado pelo delito. Nas palavras de Macedo Soares: "O casamento apaga o delicto, restituindo à mulher a posição que ocupava na sociedade". ${ }^{56}$ Como dito, o casamento seria uma forma de reparar o dano cometido contra a sociedade, contra a família da ofendida e contra a ofendida; desta forma,

\footnotetext{
54 CASTRO, Francisco José Viveiros de. Os Delictos contra a honra da mulher. 2. ed. Rio de Janeiro: Livraria Editora Freitas Bastos, Freitas Bastos \& CIA, 1932. p. 24.

55 Declaração dada pelo acusado Lycurgo Alves Guimarães a fls. 49 do processo ${ }^{\circ} 1595$, cx.76, 1898, processo este que se encontra no acervo do Arquivo Histórico Municipal "Capitão Hipólito Antônio Pinheiro" na cidade de Franca, São Paulo.
}

56 SOARES, Oscar de Macedo. Código Penal da República dos Estados Unidos do Brasil. 5. ed. Rio de Janeiro: H.Garnier, 1910. p. 561. 
não faria mais sentido punir o "criminoso" sendo que ele próprio conseguiu "curar" o dano causado; assim afirmava Macedo Soares:

O casamento é reparação voluntaria do damno causado, e desde que se realise constitue uma dirimente, que suspende a execução da pena se o desuctor casou-se depois de entrar no cumprimento, ou impede a execução ou mesmo põe termo ao processo, se o casamento realisou-se antes. ${ }^{57}$

\section{CONSIDERAÇÕES FINAIS}

Como visto, a diferenciação de tratamento entre os sexos por parte do direito era nítida, tanto na legislação quanto na prática. Hoje, a Constituição Federal do Brasil assegura o tratamento igualitário para os gêneros através de seu art. $5^{\circ}$, ao afirmar o seguinte:

Art. $5^{\circ}$ Todos são iguais perante a lei, sem distinção de qualquer natureza, garantindo-se aos brasileiros e aos estrangeiros residentes no País a inviolabilidade do direito à vida, à liberdade, à igualdade, à segurança e à propriedade, nos termos seguintes: I - homens e mulheres são iguais em direitos e obrigações, nos termos desta Constituição. (art. $5^{\circ}$, I, $\mathrm{CF} / 88$ ).

Conforme o inciso I do Art. $5^{\circ}$ da Constituição Federal, todos são iguais perante a lei, iguais em direitos e obrigações; deste modo, homens e mulheres devem ser tratados da mesma forma pelo ordenamento jurídico, sem distinção ou preconceito. Este artigo da Constituição representa alguns dos direitos e garantias fundamentais, que devem ser estendidos a todas as pessoas, independentemente do estilo de vida, profissão ou gênero, todos devem ter os mesmos direitos e obrigações, seja homem ou mulher, rico ou pobre.

57 SOARES, Oscar de Macedo. Código Penal da República dos Estados Unidos do Brasil. 5. ed. Rio de Janeiro: H.Garnier, 1910. p. 562. 
Porém, na prática não é sempre assim que ocorre: a luta pela igualdade de tratamento ainda é ampla e pode ser observada através dos inúmeros movimentos feministas atuais. Ainda hoje a mulher é vista como uma guardiã da honra da família, sendo-lhe imposta uma conduta recatada, sem liberdade sexual e os seus comportamentos que afrontam os padrões estabelecidos e aceitos pela maioria são apontados como uma ofensa a moral e aos bons costumes.

Apesar de o ordenamento jurídico buscar cada vez mais a real igualdade de tratamento entre homens e mulheres, na prática frequentemente se mantém a mesma forma de pensar que era presente no século XIX. Ainda é forte a resistência em se reconhecer os novos papéis desempenhados pela mulher dentro da sociedade. Mesmo hoje, mulheres sofrem discriminação e têm seus direitos restringidos por motivos semelhantes aos do século XIX; as que não se enquadram naquele mesmo antigo modelo de "mulher honesta" sofrem discriminação e têm seus direitos afetados na prática, conforme aponta Marina Berenice Dias:

Em face de uma visão estereotipada da mulher, exige a Justiça uma atitude de recato, impondo-lhe uma situação de dependência. Persiste nos julgados uma tendência eminentemente protecionista, o que dispõe de uma dupla moral. Nas decisões judiciais, aparecem com extrema frequência os termos: inocência da mulher, conduta desregrada, perversidade, comportamento extravagante, vida dissoluta, situação moralmente irregular, expressões que contêm forte carga ideológica. Em alguns temas, vê-se com bastante clareza que, ao ser feita uma avaliação comportamental dentro de requisitos de adequação a determinados papéis sociais, é desconsiderada a liberdade da mulher. ${ }^{58}$

Isto demonstra que até o momento, a sociedade ainda possui a mesma linha de pensamento do século XIX, buscando dar um tratamento diferente a mulher como forma de manter a honra, os bons costumes, a moral da família em segurança, ainda se encontra presente uma grande

58 DIAS, Maria Berenice. Mulher e Igualdade. Disponível em: http://www.maria berenice.com.br/uploads/24_-_mulher_e_igualdade.pdf, http://www.mariaberenice.com. br/pt/mulher-e-igualdade.cont . Acesso em: 29 ago. 2015. p. 1. 
preocupação com a conduta moral da mulher. Desta forma as mulheres, frequentemente, são discriminadas por não possuírem as características que a sociedade tanto valoriza; sendo assim, os seus direitos não são tão facilmente assegurados. Como já foi mencionado, isto não ocorre da mesma forma com os homens, pois estes não são responsáveis por guardar a honra da família da mesma forma que as mulheres, então sua conduta moral não é do mesmo modo questionada, e seus atos são mais toleráveis, pois não são tão danosos à honra familiar aos olhos da sociedade.

$\mathrm{Na}$ visão da sociedade do século XIX, as mulheres que tinham de sair para trabalhar, que não se conservassem dentro do lar doméstico, eram mal vistas, e muitas vezes não tinham todos os seus direitos assegurados. Este modo de pensar ainda se encontra, de certa forma, impregnado na sociedade: constantemente, mulheres são vítimas de preconceito por não seguirem aquele mesmo modelo ideal de "honestidade feminina" do século XIX. Este panorama está cada vez mais em discussão: movimentos feministas lutam pelo direito de igualdade de tratamento das mulheres, pois não é justo uma pessoa ter seus direitos até mesmo negados por não se enquadrar no papel de guardiã da honra e dos bons costumes; isto é inadmissível em um Estado Democrático de Direito que, nas palavras de Gilmar Mendes, deve se empenhar em "assegurar aos seus cidadãos o exercício efetivo não somente dos direitos civis e políticos, mas também e, sobretudo dos direitos econômicos, sociais e culturais". ${ }^{99}$

Deste modo, são legítimos os movimentos que lutam pelo tratamento igualitário e pela real efetivação do principio da igualdade de gênero previsto na Constituição Federal do Brasil. É preciso afastar esta visão retrógrada de que a mulher é o "escudo protetor" da honra, e que ela deve seguir o padrão social, ser "honesta", para poder ter todos os seus direitos assegurados. Conforme prevê a Constituição, todos são iguais perante a lei; não se pode mais discriminar uma pessoa, muito menos restringir seus direitos levando em conta a sua conduta sexual ou sua suposta "honestidade".

\section{REFERÊNCIAS BIBLIOGRÁFICAS}

${ }^{59}$ MENDES, Gilmar Ferreira; COELHO, Inocêncio Mártires; BRANCO, Paulo Gustavo Gonet. Curso de Direito Constitucional. 2. ed. São Paulo: Saraiva, 2008. p. 149. 
Acervo do Arquivo Histórico Municipal “Capitão Hipólito Antônio Pinheiro". Franca, São Paulo.

CASTRO, Francisco José Viveiros de. Os Delictos contra a honra da mulher. 2. ed. Rio de Janeiro: Livraria Editora Freitas Bastos, Freitas Bastos \& CIA, 1932.

DIAS, Maria Berenice. Mulher e Igualdade. Disponível em: http://www.mariaberenice.com.br/uploads/24_-

_mulher_e_igualdade.pdf

http://www.mariaberenice.com.br/pt/mulher-e-igualdade.cont Acesso em: 29 ago. 2015.

Decreto $\mathrm{N}^{\circ}$ 847, de 11 de outubro de 1890. Codigo Penal dos Estados Unidos do Brazil. Disponível em: http://www2.camara.leg.br/legin/fed/decret/1824-1899/decreto847-11-outubro-1890-503086-publicacaooriginal-1-pe.html Acesso em: 23 jul. 2015.

Lei de 16 de dezembro de 1830. Codigo Criminal do Imperio do Brazil. Disponível em:

http://www.planalto.gov.br/ccivil_03/leis/LIM/LIM-16-12-

1830.htm . Acesso em: 23 jul. 2015.

MARTINS, Carlos. Saber Jurídico, Criminalidade e Controle da Sexualidade na "República dos Bacharéis". V Congresso Internacional de História, 2011, ISSN 2175-6627 (CD-ROM), ISSN 2175-4446 (ON-LINE). Disponível em: http://www.cih.uem.br/anais/2011/trabalhos/42.pdf . Acesso em: 23 jul. 2015

MENDES, Gilmar Ferreira; COELHO, Inocêncio Mártires; BRANCO, Paulo Gustavo Gonet. Curso de Direito Constitucional. 2. ed. São Paulo: Saraiva, 2008.

SOARES, Oscar de Macedo. Código Penal da República dos Estados Unidos do Brasil. 5. ed. Rio de Janeiro: H.Garnier, 1910.

VIEIRA, Taís Elaine do Nascimento. Status jurídico da mulher brasileira no século XIX. Revista Transdisciplinar Logos e Veritas, Vol. 01, $\mathrm{n}^{\mathrm{o}}$ 01, 2014, pp. 42-46, ISSN 23189614. Disponível em: http://revistalogoseveritas.inf.br/lev/wpcontent/uploads/2014/01/09 _Status-juridico-da-mulher-brasileira-no-seculo-XIX.pdf Acesso em: 23 jul. 2015. 